\title{
Aerobic Membrane Bioreactor for Wastewater Treatment - Performance Under Substrate-Limited Conditions
}

\author{
Sebastián Delgado, Rafael Villarroel, \\ Enrique González and Miriam Morales \\ Department of Chemical Engineering, Faculty of Chemistry, University of La Laguna, \\ Spain
}

\section{Introduction}

It is widely known that many regions in the world have scarce water resources. In these areas the groundwater aquifers are also found to be in a critical condition as a result of overexploitation. That is why, in such regions, the reuse of wastewater is a common practice and the competent authorities undertake multiple courses of action to encourage its reuse. Legislation implementing the reclaimed wastewater reuse is likewise very demanding in terms of quality and health and safety, which has resulted in the application of new technologies for water treatment and purification. Among the new emerging technologies appears the use of micro and ultrafiltration membranes as highly efficient systems, which are economically feasible for obtaining high quality recycled water.

Over the last two decades the technology of membrane bioreactors (MBRs) has reached a significant market share in wastewater treatment and it is expected to grow at a compound annual growth rate (CAGR) of $13.2 \%$, higher than that of other advanced technologies and other membrane processes, increasing its market value from \$ 337 million in 2010 to 627 million in 2015 (BCC, 2011). Aerobic MBRs represent an important technical option for wastewater reuse, being very compact and efficient systems for separating suspended and colloidal matter, which are able to achieve the highest effluent quality standards for disinfection and clarification. The main limitation for their widespread application is their high energy demand - between 0.45 and $0.65 \mathrm{kWh} \mathrm{m}^{-3}$ for the highest optimum operation from a demonstration plant, according to recent studies (Garcés et al., 2007; Tao et al., 2009).

The advantages of this process over the conventional activated sludge process are widely known (Judd, 2010), among these one of the most cited is the reduction in sludge production which results from operation at high solid retention time (SRT). However, its consequences for the structure and metabolism of the microbial suspensions need to be studied in detail.

Generally, we would expect that microorganisms subjected to severe substrate limitation should preferentially meet their maintenance energy requirements instead of producing additional biomass (Wei et al., 2003). This substrate limitation imposed on an MBR, by operating at low food-to-microorganism ratios $(\mathrm{F} / \mathrm{M})$, should modify the activity and characteristics of the sludge and could be the key factor for determining the process performance, particularly the membrane filtration (Trussell et al., 2006). 
Biokinetic models are widely used to design activated sludge process. Knowledge of biokinetics parameters allows modelling of the process including the substrate biodegradation rate and biomass growth. At low growth conditions, as is demanded in MBRs, other processes apart from microbial growth have to be taken into consideration. These have been recognized as the maintenance energy requirement, endogenous respiration and subsequent cryptic growth (Van Loosdrecht \& Hence, 1999). Macroscopically they cannot be perceived, but, from a practical point of view, the global process can be described by Pirt's equation (Pirt, 1965).

Although there are several experiences with membrane bioreactors working without biomass purge (Rosenberger et al., 2002a; Pollice et al., 2004; Laera et al., 2005), none of these authors apply any kinetics models to describe process performance. Furthermore, these results were obtained in similar conditions, by treating raw municipal wastewater with a high substrate concentration, and it is interesting to compare this behaviour with an MBR treating wastewater with a low organic load. Additionally, not enough is known about the morphology and extracellular polymeric substance (EPS) production for total sludge retention and low $\mathrm{F} / \mathrm{M}$ ratios.

The aim of this chapter is to summarize the current status of membrane bioreactor technology for wastewater treatment (Section 2.1). The advantages against the conventional activated sludge process and technological challenges are assessed (Section 2.2). Some design and operation trends, based on full-scale experience, are reviewed (Section 2.3). To discuss both fundamental aspects, biotreatment and filtration, some experimental results are presented. Special attention was given to the microbial growth modelling (Section 4.1.1), biomass characterisation (Sections 4.1.2 to 4.1.5) and membrane fouling mechanisms (Section 4.2). Some of these results have at the same time been compared with biomass from a conventional activated sludge process (CAS) operated in parallel.

\section{Membrane bioreactor (MBR) technology}

\subsection{Current status and process description}

The current penetration in the wastewater treatment market of the membrane bioreactors gives an idea of the degree of maturity reached by this technology. The most cited market analysis report indicates an annual growth rate of $13.2 \%$ and predicts a global market value of \$ 627 million in 2015 (BCC, 2011). Actually MBRs have been implemented in more than 200 countries (Icon, 2008). Particularly striking is the case of China or some European countries with an implementation rate of over $50 \%$ and $20 \%$, respectively.

This technological maturity in urban wastewater market is also reflected in two main issues: the diversity of technology suppliers and the upward trend in plant size. Since 1990, the number of MBR membrane module products has grown exponentially until reaching over 50 different providers by the end of 2009 (Judd, 2010). However, globally, the market is dominated by three suppliers: Kubota, Mitsubishi Rayon and GE Zenon, which held about $85-90 \%$ of the urban wastewater market (Pearce, 2008). In regard to the largest MBRs, there are 8 plants with a peak design capacity greater than 50 MLD (Table 1), all of them constructed before 2007 (Judd, 2010).

MBR technology is based on the combination of conventional activated sludge treatment together with a process filtration through a membrane with a pore size between $10 \mathrm{~nm}$ and 0.4 microns (micro/ultrafiltration), which allows sludge separation. The membrane is a barrier that retains all particles, colloids, bacteria and viruses, providing a complete 
disinfection of treated water. Furthermore, it can operate at higher concentrations of sludge (up to $12 \mathrm{~g} / 1$ instead of the usual $4 \mathrm{~g} / 1$ in conventional systems), which significantly reduces the volume of the reactors and sludge production.

\begin{tabular}{|l|l|c|c|}
\hline Project & Technology & Date & DMDF (MLD) \\
\hline Shending River, China & Beijing Origin Water & 2010 & 120 \\
\hline Wenyu River, China & Asahi K/ Beijing Origin Water & 2007 & 100 \\
\hline Johns Creek, GA & GE Zenon & 2009 & 94 \\
\hline Beixiaohe, China & Siemens & 2008 & 78 \\
\hline Al Ansah, Muscat, Oman & Kubota & 2010 & 78 \\
\hline Peoria, AZ & GE Zenon & 2008 & 76 \\
\hline Cleveland Bay, Australia & GE Zenon & 2007 & 75 \\
\hline Sabadell, Spain & Kubota & 2009 & 55 \\
\hline DMDF: Design maximum daily flow; MLD: Megalitres per day. & \\
\hline
\end{tabular}

Table 1. The largest 8 MBR plants (adapted from Judd, 2010).

Although there are two main process configurations of biomass rejection MBRs, submerged or immersed (iMBR) and sidestream (sMBR), the immersed configuration is the most widely used in municipal wastewater treatment due to lower associated costs of operation (e.g., LeClech et al., 2005a). In this configuration, the module is placed directly into the process tank and is thus less energy-intensive. As a result, it is only necessary to create a slight vacuum inside the membrane module, measured as transmembrane pressure (TMP), for filtration. For the immersed configuration, there are basically two types of commercial membrane modules available: flat sheet (FS), which is exemplified by the Kubota technology, and hollow fiber (HF) such as those supplied by GE Zenon or Mitsubishi Rayon. HF allows a higher packing density since it has a thinner space between membranes compared to FS. However, this makes it more susceptible to membrane clogging and/or sludging, and it can also make cleaning more difficult. Regarding the membrane material used for an iMBR, fluorinated and sulphonated polymers (polyvinylidene difluoride, polyethersulfone, in particular) dominate in commercial membrane MBR products (Santos \& Judd, 2010).

For another approach to the analysis of technology maturity we might take a review of the research conducted on the MBR during the last decades. It is worth noting that considerable scientific interest has been aroused in recent years in this field. Santos et al. (2010) identified 1450 scientific papers published between 1990 and 2009, with a year-by-year increase of $20 \%$ from 1994 onwards. If we analyze this literature, the most cited research topic is membrane fouling (about 30\%). In fact, scientific reviews have been published periodically that have analyzed in depth recent advances in the study of the mechanisms and factors that contribute to membrane fouling in MBR (Chang et al., 2002, Le-Clech et al, 2006, Meng et al ., 2009, Drews, 2010). Generally, these factors have been classified in four distinct groups: nature of the sludge, operating parameters, membrane/module characteristics and feed wastewater composition. However, although membrane fouling is an important issue in MBR operation, recent surveys of full-scale practitioners (Le-Clech et al., 2005b; Santos et al. 2010) show that pre-treatment and screening, membrane and aerator clogging, loss of membrane integrity, production of biosolids and other issues related to hydraulic overloading or system design, are of concern for MBR users. 


\subsection{Advantages and challenges}

As already stated, MBRs represent an important technical option for wastewater treatment and reuse, being very compact and efficient systems for separation of suspended and colloidal matter and enabling high quality, disinfected effluents to be achieved. A key advantage of these MBR systems is complete biomass retention in the aerobic reactor, which decouples the sludge retention time (SRT) from the hydraulic retention time (HRT), allowing biomass concentrations to increase in the reaction basin, thus facilitating relatively smaller reactors or/and higher organic loading rates (ORL). In addition, the process is more compact than a conventional activated sludge process (CAS), removing 3 individual processes of the conventional scheme and the feed wastewater only needs to be screened (1$3 \mathrm{~mm}$ ) just prior to removal of larger solids that could damage the membranes (Figure 1).

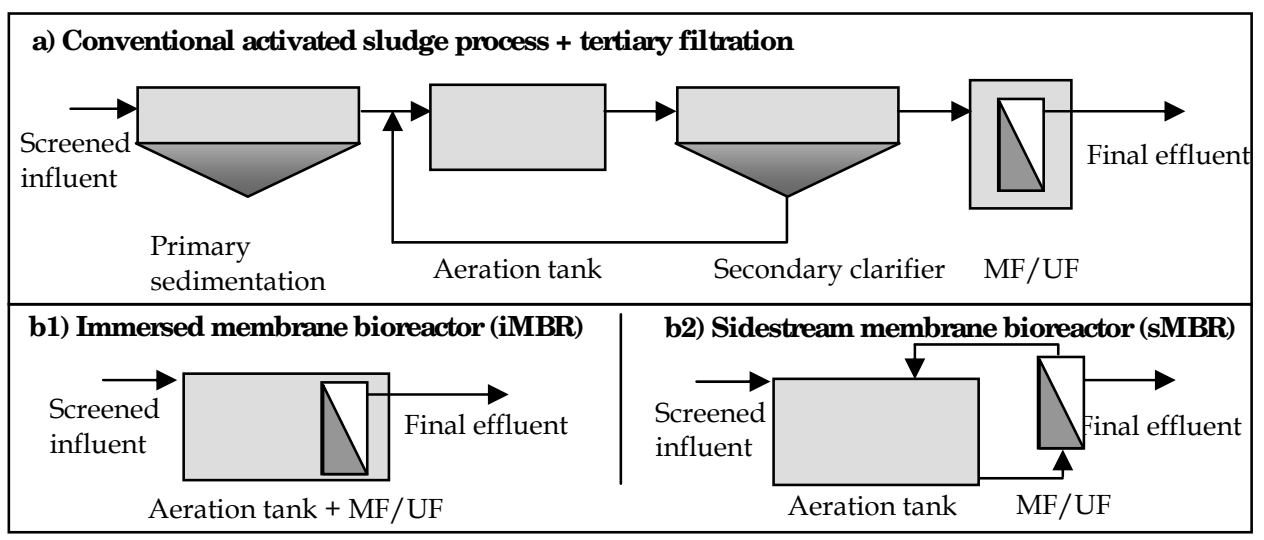

Fig. 1. Conventional activated sludge process (a) and MBR in both configurations: immersed (b1) and sidestream (b2)

Notwithstanding the advantages of MBRs, the widespread implantation is limited by its high costs, both capital and operating expenditure (CAPEX and OPEX), mainly due to membrane installation and replacement and high energy demand. This high energy demand in comparison with a CAS, is closely associated with strategies for avoiding/mitigating membrane fouling (70\% of the total energy demand for iMBR) (Verrech et al., 2008; Verrech et al., 2010). Fouling is the restriction, occlusion or blocking of membrane pores or cake building by solids accumulation on the membrane surface during operation which leads to membrane permeability loss. The complexity of this phenomenon is linked to the presence of particles and macromolecules with very different sizes and the biological nature of the microbial suspensions, which results in a very heterogenic system. Meanwhile, the dynamic behaviour of the filtration process adds a particular complication to the fouling mechanisms (Le-Clech et al., 2006). Furthermore, permeability loss can also be caused by channel clogging, which is the formation of solid deposit in the voids of the membrane modules due to local breakdown of crossflow conditions (Figure 2). In addition, there are other operational problems, such as the complexity of the membrane processes (including specific procedures for cleaning), the tendency to form foam (partly due to excessive aeration), the smaller sludge dewatering capacity and the high sensitivity shock loads. 


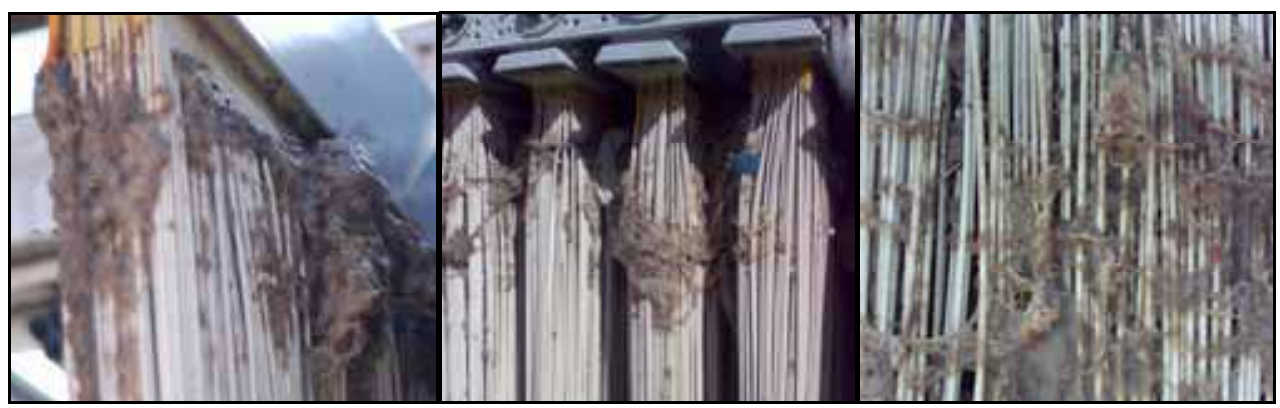

Fig. 2. a/b/c. Membrane module clogged. Debris can be observed located between the top headers modules forming a bridge between them (Morro Jable wastewater treatment plant, Canary Island, Spain; courtesy of CANARAGUA, S.A.)

For the immersed configuration, the operating strategy to control membrane fouling, (impacting directly or indirectly on CAPEX and OPEX) includes the following:

i. selecting an appropriate permeate flux,

ii. scouring of membrane surface by aeration,

iii. applying physical cleaning techniques, like backflushing (when permeate is used to flush the membrane backwards) and relaxation (when no filtration takes place), and

iv. applying chemical cleanings protocols, with different frequency and intensity (maintenance cleaning and recovery cleaning).

The fist concern, selecting an appropriate permeate flux, is determined by the classical tradeoff problem: at higher fluxes CAPEX decreases while OPEX increases. High fluxes are desirable to reduce the membrane required (i.e. reduce CAPEX), however, membrane fouling increases with flux, which results in a higher membrane scouring demand and more frequent cleaning to control membrane fouling (i.e. increase OPEX). Furthermore, the correlation between membrane fouling and flux is not only influenced by hydrodynamics and cleaning protocols but also by feedwater characteristics and biological conditions. As a result, deciding a flux value depends on the analysis of empirical data obtained from pilot and full-scale experiments or available in the recent literature .

The second concern is membrane scouring. Ever since the iMBR appeared, air sparging has been widely used to mitigate fouling by constant scouring of the membrane surface (Cui et al., 2003) or by causing lateral fibre movement in HF configuration (Wicaksana et al., 2006). While the membrane fouling has been studied and mathematically modelled in classic filtration regimes (crossflow and dead-end) (e.g. Foley, 2006), the effect of turbulence induced by gas sparging in iMBR systems is still being assessed (Drews, 2010). As is well known, it has a clear contribution to minimizing the fouling problem, and therefore, a deeper understanding is extremely important in order to optimise aeration mode and rate, which has been proved to be one of its major operational costs.

The third concern is related to methods of physical cleaning (relaxation and backflushing) that have been incorporated as standard operation mode in MBRs. These techniques have successfully been proved to remove reversible fouling caused by pore blocking or sludge cake. For backflushing, the key parameters in the design of physical cleaning have been identified as frequency, duration, the ratio between these two parameters and its intensity (Le-Clech et al., 2006), and the same key parameters are expected for relaxation (with the exception of intensity). However, there is a knowledge gap in the inter-relationships between those parameters and the imposed permeate flux, especially when comparing both methods to obtain the same water productivity (Wu et al., 2008). 
Finally, the fourth concern is chemical cleaning. Chemical cleaning is required when fouling cannot be removed by membrane surface scouring or physical cleaning methods. Although there are several types of chemical reagents used in membrane cleaning, in most full-scale facilities, two types of chemical reagents are commonly used: oxidants (e.g. $\mathrm{NaOCl}$ ) for removing organic foulants (e.g. humic substances, proteins, carbohydrates), and organic acids (e.g. citric) for removing inorganic scalants. Basically, two objectives are pursued in the addition of chemical reagents: maintaining membrane permeability and permeability recovery. Maintenance cleaning is applied routinely via a chemically enhanced backflush where the reagent, at moderate concentration, is introduced with the permeate. In contrast, recovery cleaning is applied when the membrane permeability decreases until reaching nonoperative values. The procedure consists of taking off the modules or draining off the membrane tanks to allow the membranes to be soaked in high concentrated reagents. Each MBR supplier has his own protocols which differ in concentrations and methods. Given its impacts on membrane lifetime and therefore on OPEX, there has recently been a growing interest in studying the influence of chemical cleaning procedures on membrane permeability maintenance and recovery (Brepols et al., 2008; Ayala et al., 2011). However, at the moment, the optimization of chemical cleaning protocols is far from being fully resolved.

\subsection{Design and operation considerations}

As was previously mentioned, the iMBR represents the most widely used configuration in large scale applications. This section gives some design and operation considerations including:

i. Pre-treatment,

ii. Design flux, hybrid systems and equalization tanks,

iii. Membrane fouling control and cleaning,

iv. Sludge retention time and biomass concentration, and

v. Membrane life

\subsubsection{Pre-treatment}

Membranes are very sensitive to damage with coarse solids such as plastics, leaves, rags and fine particles like hair from wastewater. In fact, a lack of good pre-treatment/screening has been recognised as a key technical problem of MBR operation (Santos and Judd, 2010a). For this reason fine screening is always required for protecting the membranes. Typically, screens with openings range between $1 \mathrm{~mm}$ ( $\mathrm{HF}$ modules) to $3 \mathrm{~mm}$ (FS modules) are common in most facilities. However, data reported by Frechen et al. (2007) for 19 MBR European plants show a more conservative plant design by reducing the screen openings to 0.5-1.0 mm for both HF and FS. Regarding primary sedimentation, it was not economically viable for small-medium sized MBR plants $\left(<50.000 \mathrm{~m}^{3} / \mathrm{d}\right)$, except for cases of retrofitting or upgrading of an existing CAS. However, for larger plants, given its advantages (smaller bioreactor volumes, reduced inert solids in the bioreactor, increased energy recovery, etc.), primary clarification can be considered. Its selection should be a compromise between energy and land cost.

\subsubsection{Design flux, hybrid systems and equalization tanks}

Membrane permeate flux is an important design and operational parameter that impacts significantly in CAPEX and OPEX. Typical operation flux rates for various full-scale iMBRs 
applied to treat municipal wastewater treatment are over 19-20 1/ $\mathrm{h} \mathrm{m}^{2}$ (Judd, 2010) with a peak flux $\left(<6 \mathrm{~h}\right.$ ) in the range $37-73 \mathrm{l} / \mathrm{h} \mathrm{m}^{2}$ (Asano et al., 2006).

A recent analysis of design and operation trends of the larger MBR plants in Europe (Lesjean et al., 2009), shows a broad difference between the design and operation flux. For Kubota systems, the designed maximum daily net fluxes are 14-48 $1 / \mathrm{h} \mathrm{m}^{2}$ (mean at $32 \mathrm{l} / \mathrm{h}$ $\mathrm{m}^{2}$ ) while for the GE Zenon modules they are 20-37 l/ $\mathrm{h} \mathrm{m}^{2}$ (mean at $29 \mathrm{l} / \mathrm{h} \mathrm{m}^{2}$ ). However, it is interesting to note that for both systems the operation net flux is over $18 \mathrm{l} / \mathrm{h} \mathrm{m}^{2}$. Further differences are the same regardless of whether this is a new plant or a retrofit, or more or less conservative designs of a specific plant. In fact, the authors indicate that the averaged trend of the design maximum net flux and operation mean flux have moderately increased

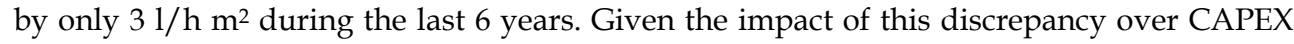
(i.e. higher membrane surface demand) and OPEX (i.e. higher membrane replacement costs) different solutions have been proposed: a plant has been designed in parallel to conventional activated sludge systems (hybrid systems), which can absorb the peak flows, or by addition of a buffer tank for flow equalisation.

In a comprehensive cost analysis of a large HF MBR plant, Verrecht et al. (2010) show the impact of both solutions on plant costs over the cycle life of the plant. While comparing a hybrid system with an MBR designed to manage maximum flow conditions, results indicate that the average energy demand for the full-flow MBR is $57 \%$ higher, as a result of underutilization of the membrane available area and excess of membrane aeration. With regard to the adding of a buffering tank, the authors pointed out that the cost of buffering would be covered by reducing the required membrane surface area. However, this solution should increase the scale size of the plant by $10 \%$ compared to CAS treating the same flow. Therefore, the authors conclude that hybrid MBR plant is the most desirable option. Examples of some full-scale facilities with this hybrid system would be the Brescia plant with GE/Zenon in Italy, or the Sabadell plant with Kubota in Spain.

\subsubsection{Membrane fouling control and cleaning}

It is generally accepted that the optimal operation of an MBR depends on understanding membrane fouling (Judd, 2007). Abatement of fouling leads to elevated energy demands and has become the main contribution to OPEX (Verrech et al., 2008). In addition, uncertainty associated with this phenomenon has led to conservative plant designs where the supplied energy is so far to be optimised.

Traditional strategies for fouling mitigation such as air sparging, physical cleaning techniques (i.e backflushing and relaxation) and chemical maintenance cleaning have been incorporated in most MBR designs as a standard operating strategy to limit fouling. Air sparging, expressed as specific aeration demand $S A D_{m}$, takes a typical value for full-scale facilities between $0.30 \mathrm{Nm}^{3} / \mathrm{h} \mathrm{m}^{2}$ (FS configuration) to $0.57 \mathrm{Nm}^{3} / \mathrm{h} \mathrm{m}^{2}$ (HF configuration). Relaxation and backflushing (only for HF) are commonly applied for 30-130 seconds every 10-25 min of filtration (Judd, 2010). Frequent maintenance cleanings (every 2-7 d) are also applied to maintain membrane permeability. However, these pre-set fixed values of key parameters, based on general background or the recommendations of membrane suppliers, lead to under-optimised systems and results in loss of permeate and high energy demand.

Recently, several authors have proposed a feedback control system for finding optimal operating conditions. For example, Smith et al. (2006) have successfully validated a control system for backflush initiation by permeability monitoring. This system automatically adjusts the backflushing frequency as a function of the membrane fouling, which results in 
a reduction of up to $40 \%$ in the backflushing water required. Ferrero et al. (2011) have used a control system at semi-industrial pilot scale trials based on monitoring membrane permeability, which achieved a energy saving between 7 to $21 \%$ with respect to minimun aeration recommended by membrane suppliers.

\subsubsection{Sludge retention time (SRT) and biomass concentration}

SRT contributes to a distinct treatment performance and membrane filtration, and therefore, to system economics. Specifically, these parameters act on biomass concentration (MLSS), generation of soluble microbial products (SMP) and oxygen transfer efficiency.

Increasing the SRT increases the sludge solids concentration and therefore, reduces bioreactor volume required. Furthermore, because of the low growth rates of some microorganisms (specifically nitrifying bacteria), a longer SRT will achieve a better treatment performance, as well as generating less sludge. In addition, it has been reported that high values of SRT can increase membrane permeability by decreasing SMP production (Trussel et al., 2006). Conversely, high solids concentration results in a higher viscosity of the microbial suspension (Rosenberger et al., 2002b), as a consequence, higher concentrations decrease air sparging efficiency and oxygen transfer rate to the microorganisms, resulting in a higher energy demand as well as increasing membrane fouling and the risk of membrane clogging. Given all of these factors, for economical reasons, most full-scale facilities are designed for MLSS range of 8-12 g/l and SRT range of 10-20 d (Asano et al., 2006; Judd, 2010).

\subsubsection{Membrane life}

As a consequence of being a relatively new technology, limited information on the life of membranes is available. However, analysis of the oldest plants evidence that membrane life can reach, or even exceed, 10 years (Verrech et al., 2010).

Recently, Ayala et al. (2011) has reported the effect of operating parameters on the permeability and integrity of cartridges taken from full-scale MBRs. Regarding permeability, a correlation of permeability loss and operation time was found, indicating that the membrane permeability reaches non-operative value after seven years of operation. The authors also suggested a significant effect of inorganic scaling on permeability loss. The correct functioning during membrane cartridge life, determined by the strength of the welding at its perimeter, appears to be related to the total volume of water permeated and the total mass of oxidant $(\mathrm{NaOCl})$ used during chemical cleanings.

\section{Experimental methodology}

\subsection{Experimental setup}

The experimental unit consisted of a cylindrical 2201 submerged membrane bioreactor (MBR) equipped with a submerged hollow-fibre membrane of $0.03 \mu \mathrm{m}$ rated pore diameter and $0.93 \mathrm{~m}^{2}$ filtering surface area (ZeeWeed ZW10) supplied by GE Water \& Process Technologies (Figure 3). The effluent (permeate) was extracted from the top header of the module under slight vacuum (transmembrane pressure lower than 0.12 bar). Fouling was controlled by coarse bubbling of air flow and by intermittent filtration of the permeate. The pilot plant (ZW10) was located in the wastewater treatment plant (WWTP) in Santa Cruz de Tenerife (Canary Islands, Spain). 


\subsection{Feedwater characteristics}

The reactor was fed with screened $(2.5 \mathrm{~mm})$ municipal wastewater. The average feed concentrations are given in Table 2. The feedwater was characterized by a high biodegradable organic fraction $\left(\mathrm{BOD}_{5} / \mathrm{COD}=0.52-0.67\right)$. Also, suspended solids in the water had a high organic fraction (VSS/TSS $=0.85-0.95$ ).

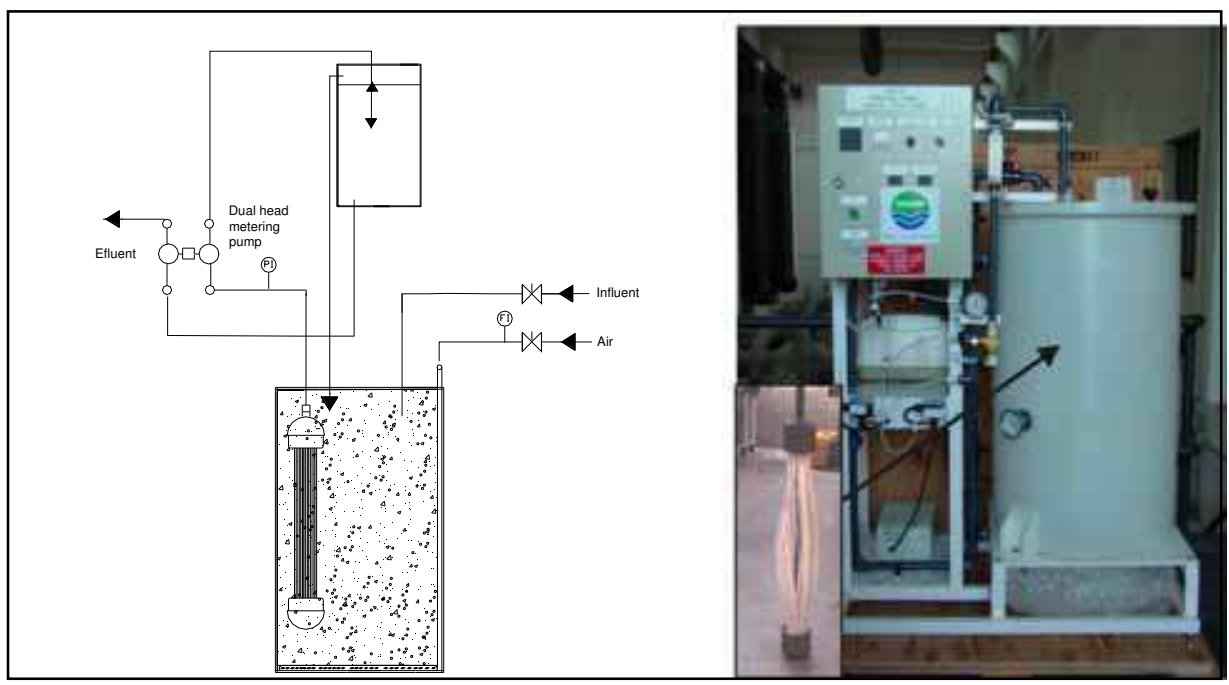

Fig. 3. Configuration and photograph of the pilot-MBR system, ZW10.

\begin{tabular}{|c|c|c|c|c|c|c|c|}
\hline & $\begin{array}{c}\mathrm{COD} \\
\mathrm{mg} / 1\end{array}$ & $\begin{array}{c}\mathrm{COD}_{\mathrm{s}^{\mathrm{a}}} \\
\mathrm{mg} / 1\end{array}$ & $\begin{array}{c}\mathrm{N}^{-\mathrm{NH}_{4}}{ }^{+} \\
\mathrm{mg} / 1\end{array}$ & $\begin{array}{c}\mathrm{N}^{-\mathrm{NO}_{2}} \\
\mathrm{mg} / 1\end{array}$ & $\begin{array}{c}\mathrm{N}^{-\mathrm{NO}_{3}} \\
\mathrm{mg} / 1\end{array}$ & $\mathrm{pH}$ & $\begin{array}{c}\mathrm{TSS} \\
\mathrm{mg} / 1\end{array}$ \\
\hline Mean & 879 & 262 & 70 & 0.07 & 2.0 & 8.1 & 830 \\
\hline Max. & 1316 & 717 & 125 & 0.35 & 8.0 & 8.3 & 2200 \\
\hline Min. & 270 & 137 & 33 & 0.03 & 1.0 & 7.7 & 150 \\
\hline
\end{tabular}

Table 2. Mean concentrations of the feedwater

\subsection{Operating conditions}

Table 3 lists operating conditions. Permeate flux was incremented from 20 to $35 \mathrm{l} /\left(\mathrm{h} \mathrm{m}^{2}\right)$ in successive experimental runs. In order to maintain a constant HRT independent from the imposed permeated flux in each run, a peristaltic pump extracted from the permeate tank the flow rate necessary to maintain the required HRT and the excess of permeate was returned to the bioreactor (see Figure 1). Chemical cleaning of the membrane with sodium hypochloride $(250 \mathrm{mg} / \mathrm{l})$ was performed at the end of each experimental run.

Air was supplied through the bottom providing oxygen and stirring. The dissolved oxygen concentration was always above $1.5 \mathrm{mg} / 1$ in the reactor operated at $23 \pm 2{ }^{\circ} \mathrm{C}$.

\subsection{Analytical methods}

Dissolved oxygen (DO) was measured using a WTW 340i. Chemical oxygen demand (COD), ammonium-nitrogen $\left(\mathrm{N}-\mathrm{NH}_{4}{ }^{+}\right)$, total suspended solids (TSS), mixed liquor suspended solids 
(MLSS), mixed liquor volatile suspended solids (MLVSS) were determined in conformity with the Standard Methods (American Public Health Association, 1992). Nitrite-nitrogen (N$\left.\mathrm{NO}_{2}{ }^{-}\right)$and Nitrate-nitrogen $\left(\mathrm{N}-\mathrm{NO}_{3}{ }^{-}\right)$were measured by spectrophotometric methods with a HACH DR 2000. Microbial floc size was measured by Coulter LS100 (Coulter, UK). Proteins were determined as bovine albumin equivalent using the protein kit assay TP0300 supplied by Sigma, following the Lowry method (Lowry et al., 1951). Polysaccharides were measured as glucose equivalent by the Dubois`method (Dubois et al., 1956).

\begin{tabular}{|l|c|c|}
\hline Parameters & Units & Value \\
\hline Sludge retention time (SRT) & days & Infinite (without purge) \\
\hline Hydraulic retention time (HRT) & hours & 24.6 \\
\hline Filtration time & seconds & 450 \\
\hline Duration of relax phase & seconds & 30 \\
\hline Aeration rate per membrane area $\left(\mathrm{SAD}_{\mathrm{m}}\right)$ & $\mathrm{Nm}^{3} / \mathrm{h} \mathrm{m}^{2}$ & 1.9 \\
\hline Permeate flux & $1 / \mathrm{h} \mathrm{m}^{2}$ & $20-35$ \\
\hline
\end{tabular}

Table 3. Operating conditions of the pilot-scale MBR

The oxygen uptake rate was measured by following the dissolved concentration with a membrane oxygen electrode in a medium without substrate (SOURe, endogenous). The sludge rheological properties were determined by using the concentric cylinder rotational viscosimeter Visco Star plus (FungiLab, Spain). The width of the annular gap was $1.0 \mathrm{~mm}$. Measurements were done at $25{ }^{\circ} \mathrm{C}$.

\section{Experimental results}

\subsection{Biological process}

\subsubsection{Maintenance kinetics}

Biomass concentration in the bioreactor is one of the most critical parameters in capital and operational costs of the process. It is known that increasing the biomass concentration reduces the bioreactor size and therefore, capital costs. However, high sludge concentration impacts on aeration efficiency (because of high viscosity) increasing membrane fouling propensity and, probably, membrane clogging (filling of the channels between the membranes with sludge solids). Therefore, a more frequent cleaning and higher aeration rate is necessary to maintain membrane permeability, which increments the operational costs. Therefore, fundamental knowledge of biomass development processes involved in the biological treatment of a MBR is required.

Figure 4 shows the typical trend of biomass evolution, expressed as total (MLSS) and volatile suspended solids (MLVSS), during the start-up and steady-state of an MBR operated without biomass purge. Biomass is developed from the microorganisms coming with the feed wastewater as the bioreactor had not been inoculated. During the initial period, biomass increased rapidly and then slower with increasing biomass concentration in the mixed liquor.

The first concern is the MLVSS/MLSS ratio, which remained within the range between 71 and $78 \%$. It is important to note that, despite operating in conditions of total sludge 
retention, this ratio remains constant throughout the experiment, indicating no significant accumulation of inorganic matter in the sludge. This may be due to the fact that a small fraction of inorganic suspended solids in the feed (5-15\%) is dissolved during the process and, therefore, does not accumulate in the sludge and leaves the system with the permeate.

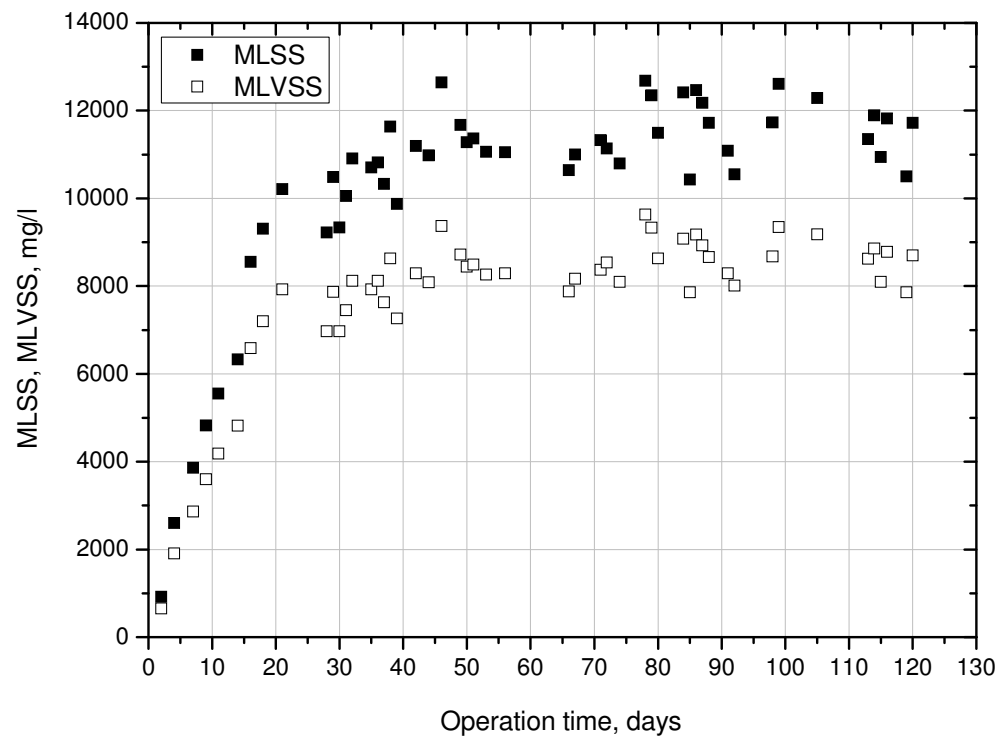

Fig. 4. Evolution of biomass concentration (MLSS and MLVSS) in the mixed liquor with operation time.

The second concern is the stabilisation value of the biomass concentration (MLSS and MLVSS), which is expected to depend on the hydraulic retention time (HRT) and COD removal, resulted in a stationary value of utilisation rate $(U)$. Figure 5 shows the evolution of $U$ with operation time where it can be observed that the system evolved until reaching a nearly constant value $(0.083 \pm 0.004 \mathrm{~kg}$ COD $/ \mathrm{kg}$ MLVSS d). A symmetrical trend can also be observed for data obtained in a previously reported research (Delgado et al., 2010) in an MBR treating biological effluent from a WWTP. In that case, the MBR was inoculated and the initial biomass evolution was characterised by a lysis process. Afterwards, a stationary vale for $U$ was reached $(0.067 \pm 0.004 \mathrm{~kg}$ COD $/ \mathrm{kg}$ MLVSS $\mathrm{d})$ independently of the fixed HRT value.

It is thought that the maintenance concept introduced by Pirt (1965) could be the reason for the equilibrium reached in the MBRs operated without biomass purge. Then, the utilisation rate can be described by the Pirt equation (1).

$$
U=\frac{r_{x}}{Y \cdot X}+k_{m, S}
$$

where $r_{s}$ is the substrate removal rate, $r_{x}$ is the biomass growth rate, $Y$ is the true sludge yield, $k_{m, S}$ is the maintenance coefficient and $X$ is the biomass concentration.

At very low growth rates (i.e. steady-state conditions), $r_{x}$ can be neglected: 


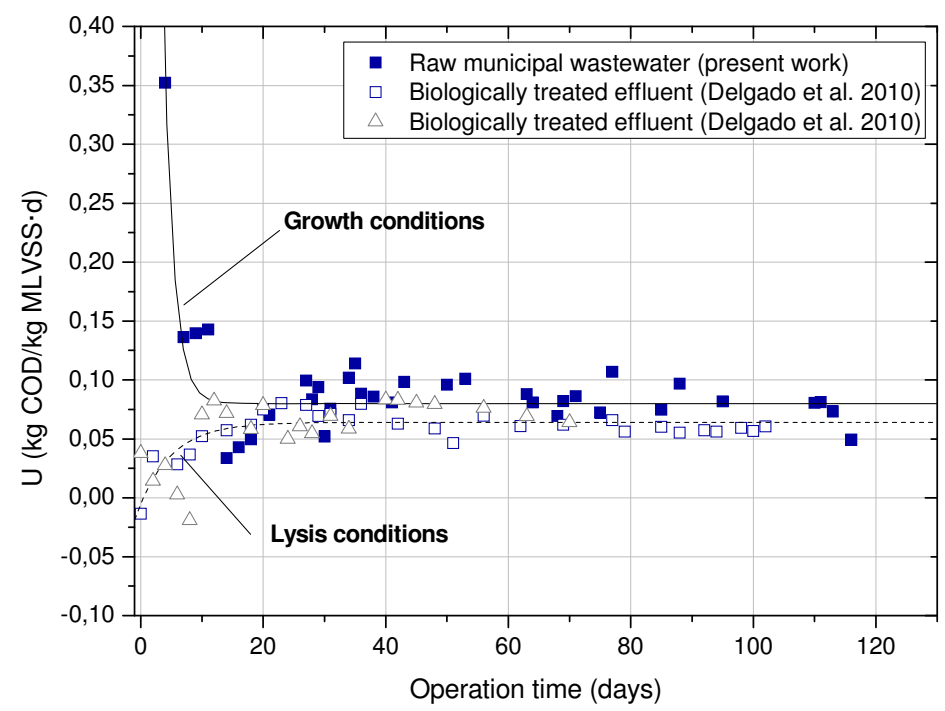

Fig. 5. Evolution of utilisation rate with operation time for MBRs treating different types of feed wastewaters.

$$
U \approx k_{m, S}
$$

Therefore, the stationary value of the utilisation rate is identical to the maintenance coefficient, which suggests that, in these substrate-limited conditions, microorganisms tend to minimize their energy requirements using the available substrate to satisfy their maintenance functions. For the presented data the best fitting parameter was $k_{m, S}=0.0035 \mathrm{~kg}$ COD/kg MLVSS h.

\subsubsection{Microbial activity: Specific endogenous oxygen uptake rate}

The measurement of the oxygen demanded by the microorganisms is a parameter frequently used for assessing aerobic activity of microbial suspensions (Vanrolleghen et al., 1995). In this sense, Pollice et al. (2004) reported that the specific endogenous respiration rates are closely related to the organic loading rates $(\mathrm{F} / \mathrm{M})$. Table 4 shows specific endogenous oxygen uptake rates $\left(\mathrm{SOUR}_{\mathrm{e}}\right)$ of sludge samples at steady-state conditions and other values reported in the literature. The SOUR $\mathrm{e}$ is considerably lower than the typical values, which confirms the maintenance energy requirement reached.

\begin{tabular}{|c|c|c|}
\hline F/M, kg COD/ kg MLVSS d & SOUR $_{\mathrm{e}}, \mathrm{kg} \mathrm{O}_{2} / \mathrm{kg}$ MLVSS d & Reference \\
\hline- & 0.118 & Coello Oviedo et al., 2003 \\
\hline 0.15 & 0.05 & Pollice et al., 2004 \\
\hline 0.08 & $0.01-0.05$ & Rodde-Pellegrin et al., 2002 \\
\hline 0.09 & $0.0084 \pm 0.03$ & This work \\
\hline
\end{tabular}

Table 4. Specific endogenous oxygen uptake rate of sludge samples 


\subsubsection{Sludge morphology}

According to the literature, flocculant ability tends to be reduced when organic substrate is lacking (e.g. Wilen et a., 2000). In an MBR operated under substrate-limited conditions these conditions of stress are imposed and therefore a floc distribution characterised by a greater number of small flocs is expected. In addition, particle size distribution plays an important role in the formation of the cake on the membrane surface. A cake made with small particles has higher specific resistance and, therefore, is less permeable than the cake formed by larger particles (Defrance et al., 2000). As a consequence, it is crucial to analyze the effect of the several substrate-limited conditions imposed over the particle size of the flocs and the presence of small non-flocculating microorganisms in mixed liquor.

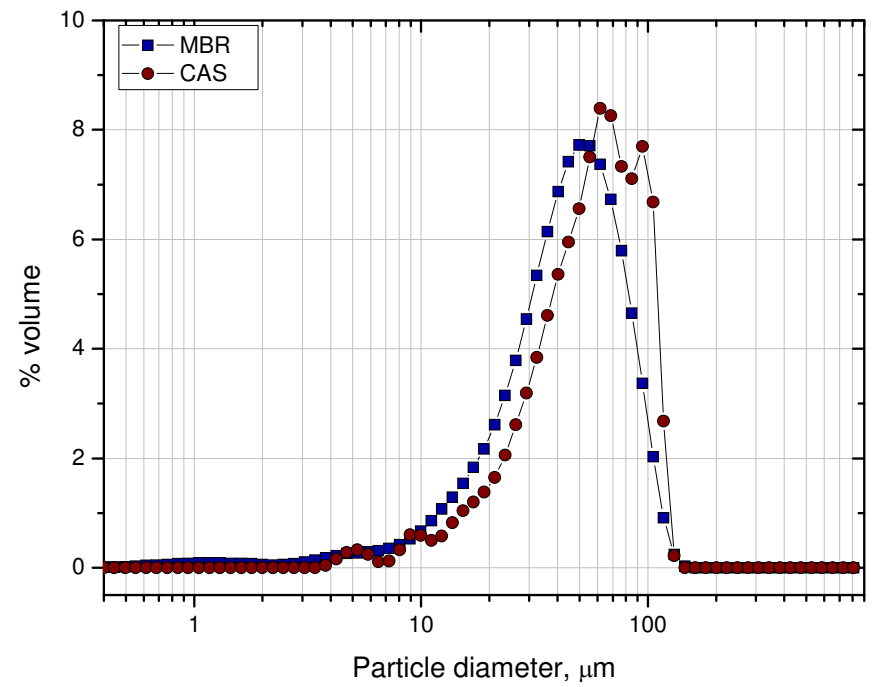

Fig. 6. Particle size distribution of MBR and CAS sludge samples.

Sludge morphology was analysed by optical microscope observations and by particle distribution measurements. In Figure 6 particle size distribution of a sludge sample at steady-state conditions is shown. Also, samples from a conventional activated sludge process (CAS) which treated the same influent were investigated and compared with the MBR sample. Figure 6 shows aggregates with bimodal distribution in CAS biomass, where $50 \%$ of the particles have a size higher than $70 \mu \mathrm{m}$. In contrast, uniform and medium-sized flocs were observed in the MBR sludge, where $40 \%$ of the particles were within the 15 to 50 $\mu \mathrm{m}$ range. Granulometric differences, which are a result of biomass separation by the membrane, are well documented in the literature (e.g. Cicek et al., 1999) and are attributable to effective particle retention by the membrane and high shear stress conditions due to air sparging for membrane fouling mitigation. Also, the low quantity of small non-floculating flocs $(<10 \mu \mathrm{m})$ could be due to the presence of higher organisms, which have traditionally been considered as predators that consume dispersed bacteria.

Alternatively, microscopic analysis of mixed liquor samples from the MBR is shown in Figure 7. The observations can be summarized into two main issues: firstly the absence of filamentous microorganisms, which can be linked to the process conditions, including high 
dissolved oxygen and low readily biodegradable substrate concentrations (Martins et al., 2004). Secondly, as a result of the low organic loading conditions, higher organisms were also expected. In this sense, a significant quantity of worms (type Aeolosoma hemprichi) developed. Similar results were reported by Zhang (2000) where a high worm density resulted in a low sludge yield (0.10-0.15 kg MLSS/ $\mathrm{kg}$ COD). Worms are considered as predators with a great potential on sludge reduction and more attention has been paid to their effectiveness in wastewater treatment recently (Wei et al., 2003).

As already stated, to operate an MBR under substrate-limited conditions enhances the presence of worms that may lead to a substantial sludge reduction and improve biomass characteristics by removing small non-floculating flocs.

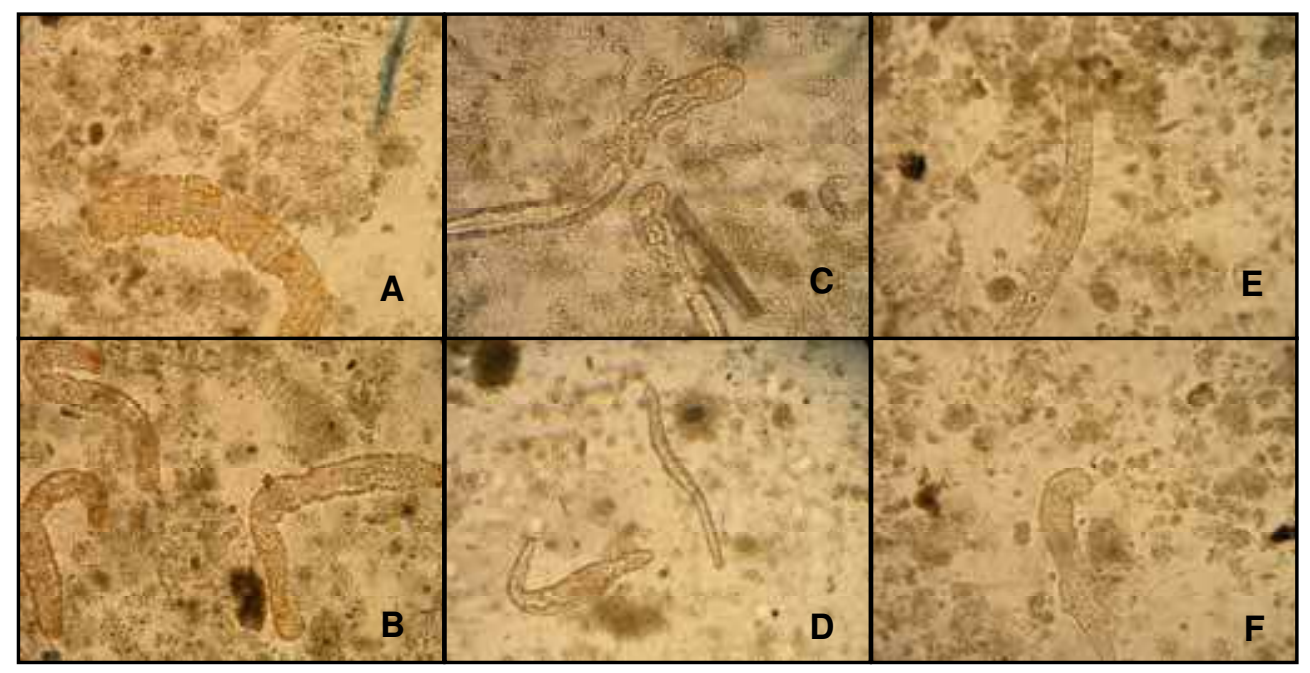

Fig. 7. Higher microorganisms found in $\operatorname{MBR}(A, B, D, F$ x20; C, E x40).

\subsubsection{Rheological properties}

Rheological properties are of crucial importance due to their effect on hydrodynamic conditions near the membrane. The rheological behavior of microbial suspensions has been described in the literature as non-Newtonian pseudoplastic fluids (Rosenberger et al., $2002 b$ ). When air is dispersed in a solid-liquid suspension a change can be seen in its rheological behavior due to the change in suspension structure: with increasing shear, the structure opens and biological aggregates are reorganized resulting in a decrease in viscosity. In addition, it is accepted that the microbial suspensions have a thixotropic nature, which means that the viscosity decreases with shear rate when samples are subject to shear stress. Rheology can be described by the Bingham model, the Ostwald model and the Herschel-Bulkley model represented by Eq. (3)-(5):

$$
\begin{aligned}
& \mu_{a}=\frac{\tau_{0}}{d v / d r}+m \\
& \mu_{a}=m \cdot\left(\frac{d v}{d r}\right)^{n-1}
\end{aligned}
$$




$$
\mu_{a}=\frac{\tau_{0}}{d v / d r}+m \cdot\left(\frac{d v}{d r}\right)^{n-1}
$$

In these models $\mu_{a}$ is the apparent viscosity, $d v / d r$ is the shear rate and $\tau_{0}, m$ and $n$ are the model parameters. From the models we may deduce that the apparent viscosity can be described as a shear rate function.

Figure 8 shows one example of apparent viscosity reduction with the shear intensity. It decreases down to $75 \%$ when the shear varied from 13 to $130 \mathrm{~s}^{-1}$. Additionally, plotting is shown according to the Bingham, Ostwald and Herschel-Bulkley models. In general, both the Ostwald model as well as the Herschel-Bulkley model fits quite well into the experimental data, while the Ostwald was selected because of its simplicity. From the equation of the curve (Figure 8) the parameter values for Ostwald model can be obtained:

$$
\begin{gathered}
n=0.41 \\
m=122 \mathrm{mPa} \mathrm{s}
\end{gathered}
$$

where $n$ is the flow behavior index and $m$ is the consistency index.

Furthermore, as shown in Figure 8, apparent viscosity $\left(\mu_{\mathrm{a}}\right)_{\text {limit }}$ can be perceived for higher values $\left(>130 \mathrm{~s}^{-1}\right)$. It does not decrease substantially with an increasing velocity gradient. Therefore, the effect of particle concentration on the viscosity can be evaluated by fitting the $\left(\mu_{\mathrm{a}}\right)_{\text {limit }}$ to the sludge concentration, measured as MLSS concentration (Figure 9). As expected, microbial suspension viscosity also increased with the MLSS concentration. This behaviour is commonly accepted in the literature (e.g. Pollice et al., 2007).

Therefore, the following equation (Eq. (6)) can estimate the limit apparent viscosity as a function of the MLSS concentration.

$$
\mu_{a_{\lim i t}}=1.1 \cdot 10^{-6} \cdot S S L M^{1.7}
$$

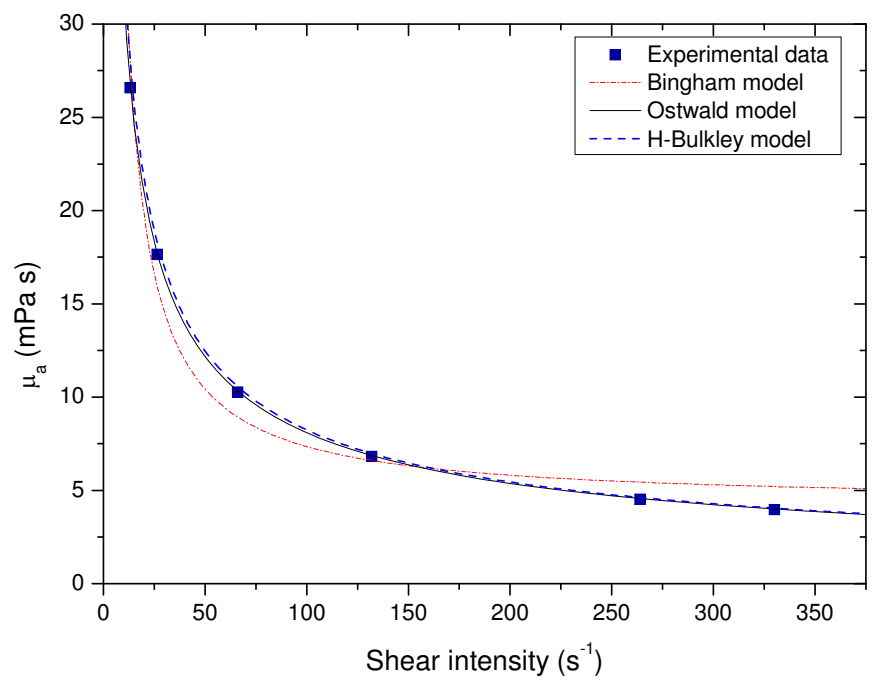

Fig. 8. Apparent viscosity against the shear intensity. 


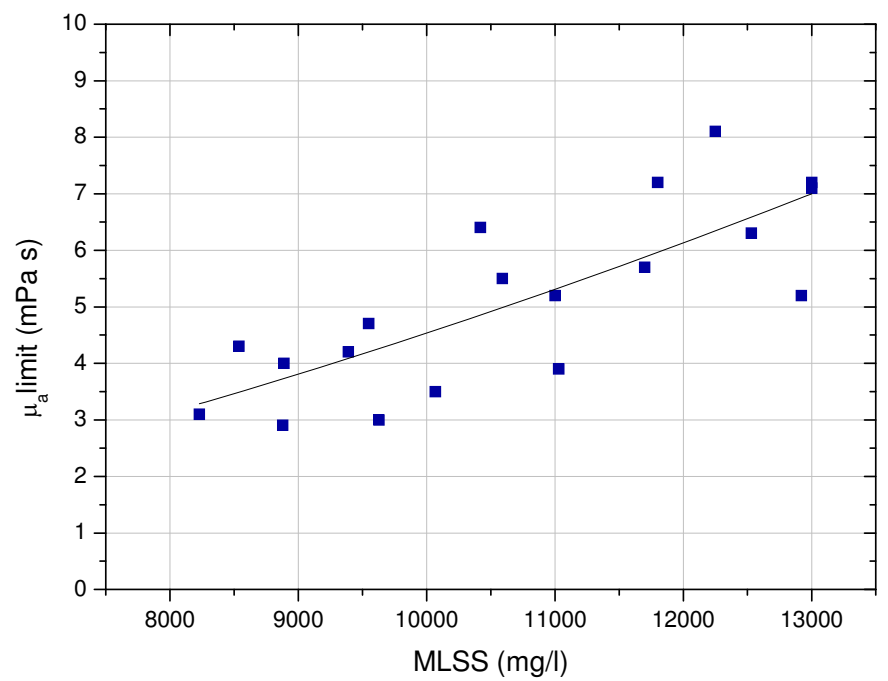

Fig. 9. Apparent viscosity limit $(\mathrm{dv} / \mathrm{dr}=264 \mathrm{~s}-1)$ against the MLSS

\subsubsection{Analysis of the liquid phase. Extracellular polymeric substances}

Extracellular polymeric substances (EPS) can be differentiated into two main types: bound EPS, which form the structure of the floc, and soluble EPS (often named soluble microbial products), which are soluble or colloidal form in the liquid medium. Recent studies have shown that the soluble and colloidal fraction plays an important role in membrane fouling (Drews, 2010). Their principle components are also generally recognised as proteins and polysaccharides (Sponza, 2002).

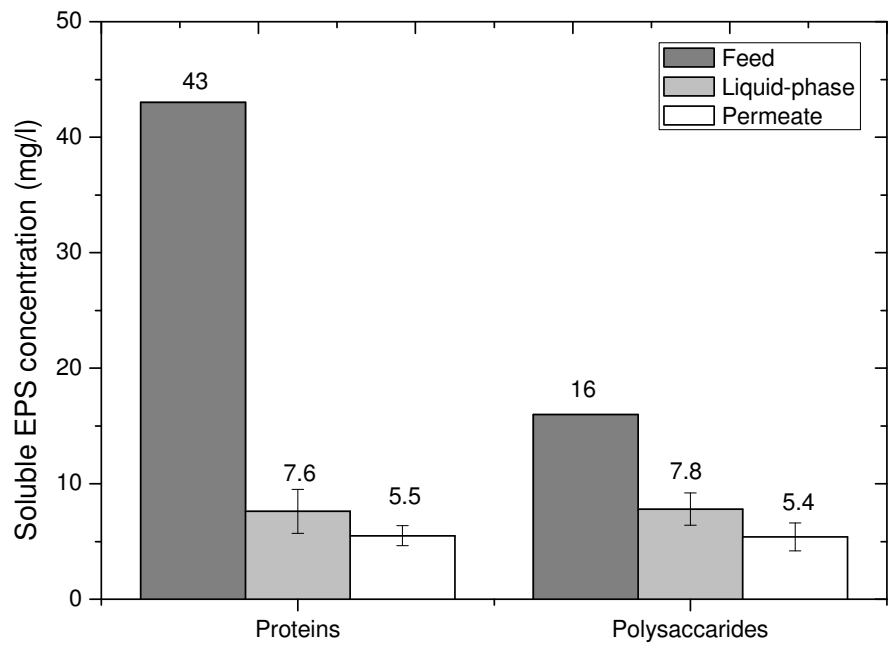

Fig. 10. Average soluble EPS concentration of feedwater, liquid-phase and permeate. 
Figure 10 compares the average concentrations of proteins and polysaccharides in the feed wastewater, in the liquid-phase and in the permeate. A significant reduction in EPS can be observed in the liquid-phase in relation to feed $(82 \%$ for proteins and $51 \%$ for polysaccharides), as a result of biological metabolism. On the other hand, the separation through the membrane of the polysaccharides is $31 \%$ and for the protein it is $28 \%$, both remaining constant throughout the experimental test. These membrane retention values are similar to those found in the literature (Rosenberger et al., 2006).

A low concentration was unexpected in the liquid-phase, as the common trend is to suppose EPS accumulation resulting from polymer retention by the membrane (Masse et al., 2006). As a consequence specific microorganisms may be assumed to develop, which can degrade polysaccharides and proteins with a slow degradation rate.

\subsection{Membrane performance}

\subsubsection{Membrane fouling characterisation: TMP profiles}

As noted in the experimental procedure, all stages were performed using the same sequence of filtration and relaxation (450 s and $30 \mathrm{~s}$, respectively). The experimental period was divided into five phases, each one operated at constant permeate flux. Membrane fouling was followed by measuring transmembrane pressure (TMP) evolution with operation time (Figure 11). Each phase finished when a pre-established TMP was reached.

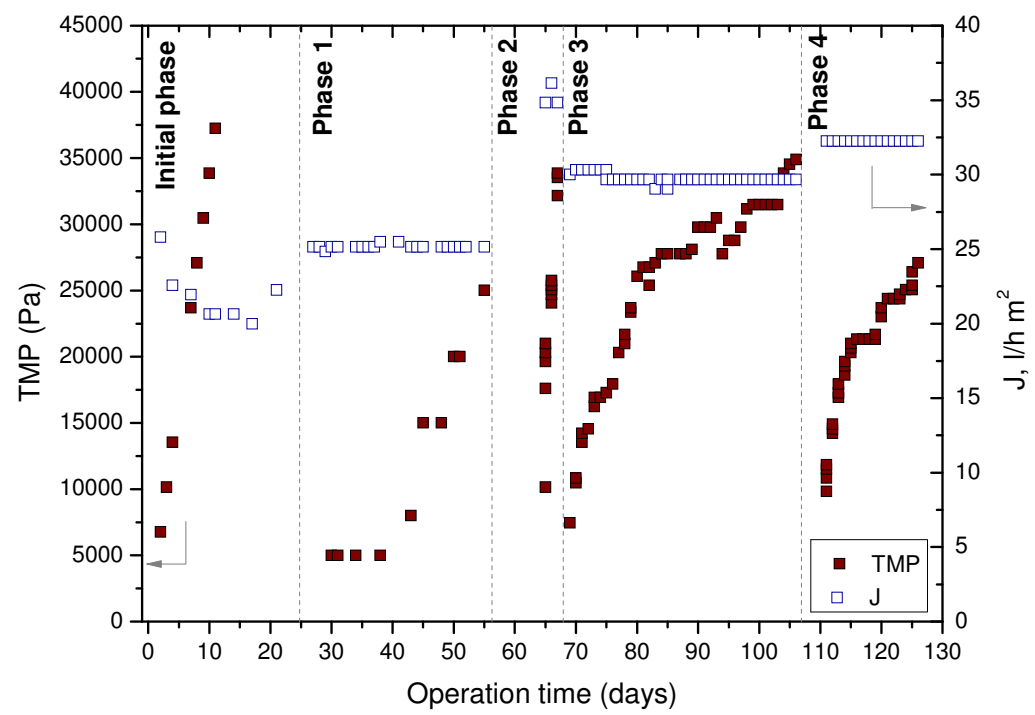

Fig. 11. Transmembrane pressure TMP and permeate flux J evolution with operation time

The initial period (Figure 11) showed a high rate of fouling $(0.011 \mathrm{~Pa} / \mathrm{s})$ despite working with relatively low permeate flux $\left(20-23 \mathrm{l} / \mathrm{h} \mathrm{m}^{2}\right)$ and without reaching a high concentration of MLSS. This could be attributed to the initial biomass development until it obtained a high level of biological degradation. During this period, it was expected that microcolloidal and soluble species would have caused irreversible pore blocking, as a result of their small size (Di Bella et al., 2006). Afterwards, we assume that the developed biomass reaches steady- 
state conditions and degrades most of the colloidal and soluble matter. Therefore, feedwater characteristics and the level of physiological biomass seem to have a significant effect of fouling propensity.

\subsubsection{Determination of sustainable flux}

The fouling rate, measured as the slope of transmembrane pressure against filtration time, has been used in many works as a fouling quantification parameter in systems operated under constant permeate flux. Experimentally, it has been found that $r_{f}$ depends exponentially on permeate flux (Figure 12). Therefore, a threshold flux value may be identified $\left(321 \mathrm{~h}^{-1} \mathrm{~m}^{-2}\right)$ above which the fouling increases at an unacceptable rate.

\subsection{Physico-chemical and microbiological quality of the permeate}

The physical and chemical quality of the permeate was assessed by the analysis of turbidity, COD and nitrogen compounds.

The permeate had an average turbidity value of $0.59 \mathrm{NTU}$, indicating a total retention of suspended solids and macro-colloidal matter. In addition, the low turbidity of the permeate registered during the whole experimental period showed that the membrane maintained its integrity.

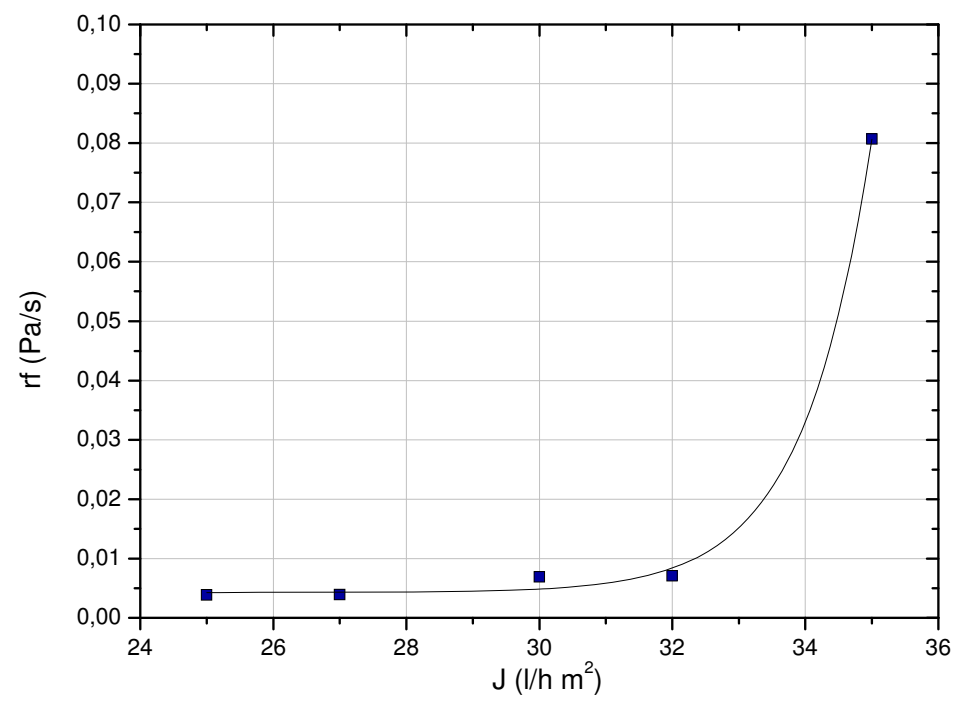

Fig. 12. Fouling rate against permeate flux.

The organic matter content was determined by measuring the COD in feed wastewater, in the permeate and in the liquid phase of the suspension. Soluble COD (CODs) was obtained by filtering through a filter paper of $0.45 \mu \mathrm{m}$ pore diameter. Figure 13 shows the COD of feedwater (COD feed), the soluble COD of feedwater $\left(\mathrm{COD}_{\mathrm{s}}\right.$ feed), the COD of the permeate $\left(\mathrm{COD}_{\mathrm{p}}\right)$ and soluble $\mathrm{COD}$ of the liquid phase $\left(\mathrm{COD}_{\mathrm{s}}\right.$ reactor) versus operating time. Typical fluctuations of feed wastewater can be seem in a real treatment plant. These oscillations lessened considerably in the permeate and in the liquid phase. 


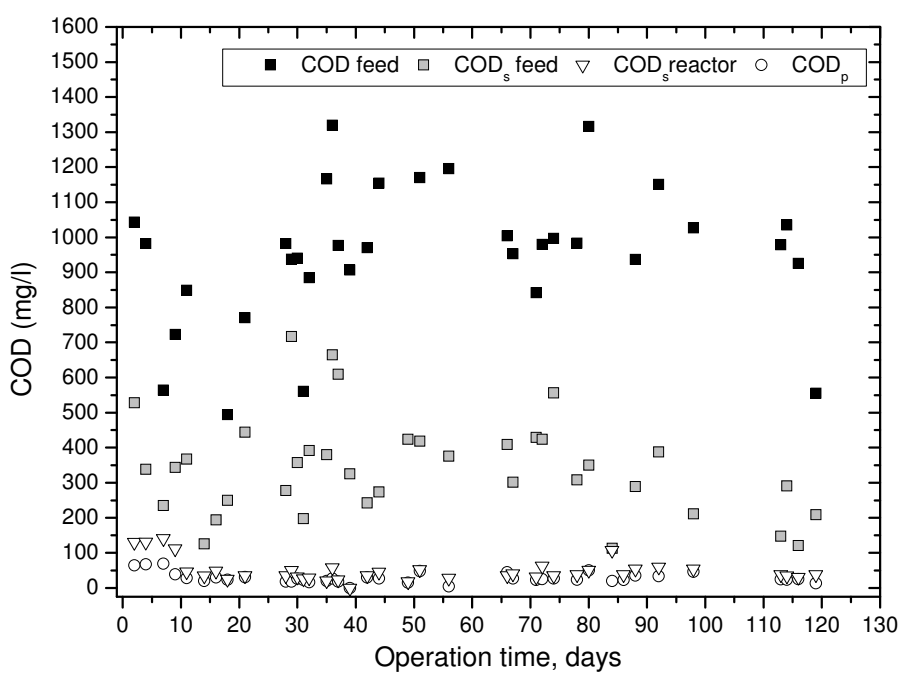

Fig. 13. COD evolution with operation time.

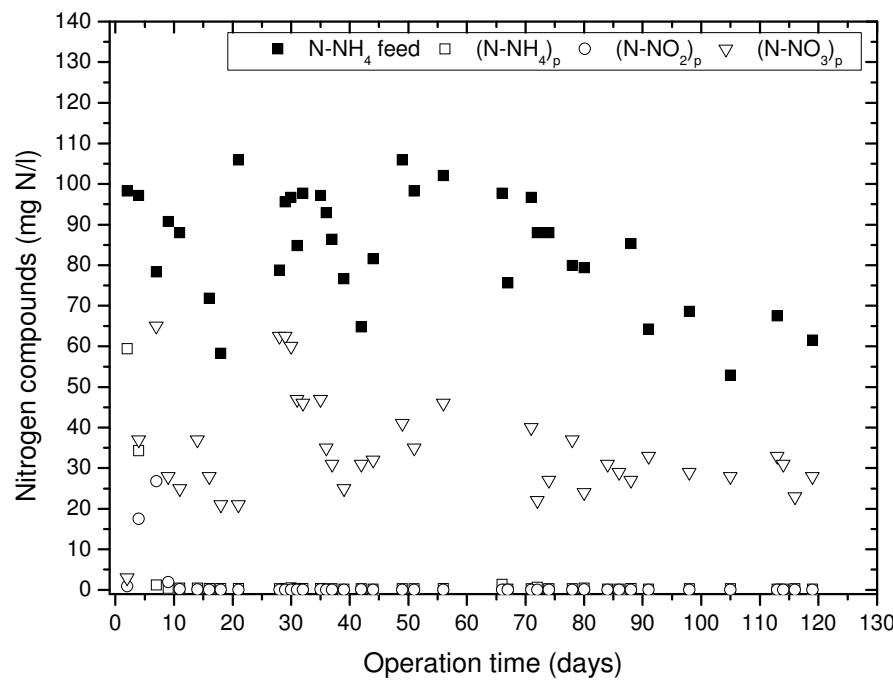

Fig. 14. Evolution of the nitrogen compounds with operation time.

As it is shown in Figure 13, there is a significant difference between the total and soluble $\mathrm{COD}$ of feed due to the presence of suspended solids. It was estimated that approximately $68 \%$ of the COD of the feed is in a particulate form. If the soluble COD of feed is compared with the soluble COD of the CODs liquid phase (CODs reactor) a removal efficiency close to $86 \%$ can be obtained, mainly due to biological degradation and only $6 \%$ is due to the membrane separation process. It should be noted that the $\mathrm{BOD}_{5}$ was not analyzed because, through frequent and trustworthy analysis of the same water, the $\mathrm{BOD}_{5} / \mathrm{COD}$ ratio was 
confirmed to be approximately constant and equal to 0.75 , so the COD analysis may be considered sufficient to determine the biodegradation produced.

Also, the evolution of the ammonium nitrogen concentration in feed wastewater $\left(\mathrm{N}-\mathrm{NH}_{4}\right.$ feed) and the nitrogen compounds of the permeate $\left(\left(\mathrm{N}^{-} \mathrm{NH}_{4}{ }^{+}\right)_{\mathrm{p}},\left(\mathrm{N}-\mathrm{NO}_{2}\right)_{\mathrm{p}},\left(\mathrm{N}^{-\mathrm{NO}_{3}}\right)_{\mathrm{p}}\right)$ were measured during the experimental period (Figure 14). As can be seen, the concentrations of nitrogen-nitrate in the permeate $\left(\mathrm{N}-\mathrm{NO}_{3}\right)_{\mathrm{p}}$ were in the range of $15-45 \mathrm{mg} / \mathrm{l}$, while nitrite and ammonia were completely removed. This is interpreted as a total oxidation of ammonium to nitrate.

As shown in Table 5, no bacterial contamination indicators, bacterial pathogens or parasites were detected in the permeate. This is attributed to the ultrafiltration membrane which has a pore diameter smaller than the size of bacteria and parasitic microorganisms, so that the membrane is an effective barrier. However, Table 5 shows the presence of viral indicators. Here, results indicate a great degree of removal $(99.8 \%$ and $95.3 \%$ for somatic coliphages and F-RNA bacteriophages, respectively).

\begin{tabular}{|c|c|c|}
\hline & Feed wastewater & Permeate $(\mathrm{N}=3)$ \\
\hline \multicolumn{3}{|l|}{ Bacteriological indicators } \\
\hline Fecal coliform ${ }^{[1]}$ & $7.7 \cdot 10^{6}$ & absence \\
\hline Escherichia Coli[1] & $7.3 \cdot 10^{6}$ & absence \\
\hline Enterococci[1] & $3.6 \cdot 10^{6}$ & absence \\
\hline Clostridium perfringens ${ }^{[1]}$ & $1.1 \cdot 10^{6}$ & absence \\
\hline \multicolumn{3}{|l|}{$\begin{array}{l}\text { Indicators of pathogenic } \\
\text { contamination }\end{array}$} \\
\hline Pseudomonas aeruginosa[1] & absence & absence \\
\hline Salmonella sp. ${ }^{[1]}$ & absence & absence \\
\hline \multicolumn{3}{|l|}{ Viral indicators } \\
\hline Somatic coliphages[2] & $3.2 \cdot 10^{6}$ & $4.3 \cdot 10^{3} \pm 1.6 \cdot 10^{3}$ \\
\hline F-RNA bacteriophages[2] & $2.3 \cdot 10^{5}$ & $1.1 \cdot 10^{4} \pm 1.6 \cdot 10^{4}$ \\
\hline \multicolumn{3}{|l|}{ Parasites } \\
\hline Giardia lamblia [3] & absence & absence \\
\hline Cryptosporidium sp. [3] & absence & absence \\
\hline
\end{tabular}

Table 5. Feed wastewater and permeate microbial results.

Permeate microbial results proved that MBR systems are able to produce permeate of high microbial quality to be used in several applications such as land irrigation, agricultural activities etc., in accordance with local standards.

\section{Conclusions}

MBRs have been proven as efficient and versatile systems for wastewater treatment over a wide spectrum of operating conditions. The treatment performance of the MBR is better than in conventional activated sludge process. A high conversion of ammonium to nitrate 
(>95\%) and constant COD removal efficiency (80-98\%) was achieved, regardless of the influent fluctuations. Microbial analysis of permeate showed the absence of bacterial indicators of contamination and parasitical microorganisms. At the same time, the membrane presented over $98 \%$ efficiency in the elimination of viral indicators.

Particularly interesting is the possibility of operating at maintenance energy level of the biomass, which significantly reduces sludge production. At these maintenance conditions, a minimal value for the carbon substrate utilization rate $\left(0.07-0.1 \mathrm{~kg}^{2}\right.$ COD kg $^{-1}$ MLVSS d $\left.^{-1}\right)$ was found and the system was operated successfully at permeate flux between 30 and $32 \mathrm{l} \mathrm{h}^{-1} \mathrm{~m}^{-2}$ and low physical cleaning frequency. As a result of carbon substrate limited conditions, EPSs were minimized and higher organisms appeared.

Biomass development at maintenance conditions can be well described by the kinetic model based on Pirt's equation.

Although there are many practical experiences for MBR design and operation, there are still some aspects that are not completely understood. Without any doubt, the most cited is membrane fouling. The complexity of this phenomenon is linked to the presence of particles and macromolecules with very different sizes and the biological nature of the microbial suspensions which results in a very heterogenic system. Meanwhile, the dynamic behaviour of the filtration process adds a particular complication to fouling mechanisms. Therefore, further investigation is required so as to ascertain which component in the suspension is the primary cause of membrane fouling.

\section{Acknowledgements}

This work has been funded by the N.R.C. (MEC project CTM2006-12226). The authors also want to express their gratitude to the MEC for a doctoral scholarship, to GE ZENON, to CANARAGUA and to BALTEN for their support and finally to the Water Analysis Laboratory of the ULL Chemical Engineering Department for analytical advice.

\section{Nomenclature}

\begin{tabular}{|c|c|}
\hline CAS & Conventional activated sludge process \\
\hline COD & Chemical oxygen demand, $\mathrm{mg} \mathrm{O}_{2} / 1$ \\
\hline EPS & Extracellular polymeric substance \\
\hline $\mathrm{F} / \mathrm{M}$ & Feed to microorganisms ratio, $\mathrm{kg}$ COD/kg MLSS d \\
\hline HRT & Hydraulic retention time, $\mathrm{h}$ \\
\hline iMBR & Immersed membrane bioreactor \\
\hline $\mathrm{J}$ & Permeate flux, $1 / \mathrm{h} \mathrm{m}^{2}$ \\
\hline MLSS & Mixed liquor total suspended solids, mg/1 \\
\hline MLVSS & Mixed liquor volatile suspended solids, mg/l \\
\hline $\mathrm{NH}_{4}-\mathrm{N}$ & Ammonium nitrogen concentration, $\mathrm{mg} / \mathrm{l}$ \\
\hline $\mathrm{NO}_{2}-\mathrm{N}$ & Nitrite nitrogen concentration, $\mathrm{mg} / \mathrm{l}$ \\
\hline $\mathrm{NO}_{3}-\mathrm{N}$ & Nitrate nitrogen concentration, $\mathrm{mg} / \mathrm{l}$ \\
\hline $\mathrm{SAD}_{\mathrm{m}}$ & Specific membrane aeration demand, $\mathrm{Nm}^{3} / \mathrm{h} \mathrm{m}^{2}$ \\
\hline SOUR $_{\mathrm{e}}$ & Specific oxygen uptake rate in endogenous conditions, $\mathrm{kg} \mathrm{O}_{2} / \mathrm{kg}$ MLVSS d \\
\hline SRT & Sludge retention time, days \\
\hline TMP & Transmembrane pressure \\
\hline $\mathrm{U}$ & Utilisation rate, $\mathrm{kg}$ COD $/ \mathrm{kg}$ MLVSS d \\
\hline
\end{tabular}




\section{References}

APHA (1992). Standard Methods for the examination of Water and Wastewater, $18^{\text {th }} \mathrm{ed}$. American Public Health Association/Water Environment Federation, Washington, DC, USA.

Asano, T.; Burton, F., Leverenz, H.; Tsuchinashi, R. \& Tchobanoglous, G. (2006). Water Reuse: Issues, Technologies and Applications. Metcalf \& Eddy/AECOM. ISBN: 978-0-07145927-3. $1^{\text {st }}$ ed.

Ayala, D.F.; Ferre, V. \& Judd. S.J. (2011). Membrane life estimation in full-scale immersed membrane bioreactors. Journal of Membrane Science (in press),

doi: 10.1016/j.memsci. 2011.03.013.

BCC. (2011). Membrane bioreactors: global markets. BCC Report MST047C. March 2011.

Brepols, C.; Dorgeloh, E.; Frechen, F.-B.; Fuchs, W. ; Haider, S.; Joss, A.; de Korte, K. ; Ruiken, C.; Schier, W.; van der Roest, H.; Wett, M. \& Wozniak, T. (2008). Upgrading and retrofitting of municipal wastewater treatment plants by means of membrane bioreactor (MBR) technology. Desalination, Vol. 231, No. 1-3, pp. 20-26.

Chang, I.S.; Le-Clech, P.; Jefferson, B. \& Judd, S. (2002). Membrane fouling in membrane bioreactors for wastewater treatment. Journal of Environmental Engineering, Vol. 128, No. 11, pp. 1018-1029.

Cicek, N., Franco, J.P., Suidan, M.T., Urbain, V., Manem, J. (1999). Characterization and comparison of a membrane bioreactor and a conventional activated-sludge system in the treatment of wastewater containing high-molecular-weight compounds. Water Environ. Res., Vol. 71, No. 1, pp. 64-70.

Coello Oviedo, M.D., López-Ramírez, J.A., Sales Márquez, D. \& Quiroga Alonso, J.M. (2003). Evolution of an activated sludge system under starvation conditions. Chem. Eng. J., Vol. 94, pp. 139-146.

Cui, Z.F., Chang, S. \& Fane, A.G. (2003). The use of gas bubbling to enhance membrane processes, Journal of Membrane Science, Vol. 221, pp. 1-35.

Defrance L., Jaffrin, M.Y.; Gupta, B.; Paullier, P. \& Geaugey, V. (2000). Contribution of various constituents on activated sludge to membrane bioreactor fouling. Bioresource Technology, Vol. 73, pp. 105-112.

Delgado, S.; Villarroel, R.; González, E. (2010). Submerged Membrane Bioreactor at Substrate-Limited Conditions: Activity and Biomass Characteristics. Water Envinonment Reseanch, Vol. 82, No. 3, pp. 202-208.

Di Bella G., Durante, F., Torregrossa, M. \& Viviani, G. (2006). The role of fouling mechanisms in submerged membrane bioreactor during the start-up. Desalination, Vol. 200, pp. 722-724.

Drews, A. (2010). Membrane fouling in membrane bioreactors-Characterisation, contradictions, cause and cures. Journal of Membrane Science, Vol. 363, No. 1-2, pp. 128.

Dubois, M.; Gilles, K.A.; Hamilton, J.K.; Rebers, P.A. \& Smith, F. (1956). Calorimetric method for determination of sugars and related substances. Anal Chem., Vol. 28, No. 3, pp. 350-356.

Ferrero, G.; Monclús, H.; Buttiglieri, G.; Comas, J. \& Rodriguez-Roda, I. (2011). Automatic control system for energy optimization in membrane bioreactors. Desalination, Vol. 268, No. 1-3, pp. 276-280.

Foley, G. (2006) A review of factors affecting filter cake properties in dead-end microfiltration of microbial suspensions. Journal of Membrane Science, Vol. 274, pp. 38-46. 
Frechen, F.B.; Schier, W.; \& Linden. C. (2008). Pre-treatment of municipal MBR applications. Desalination, Vol. 231, No. 1-3, pp. 108-114.

Garcés, W.; De Wilde, C.; Thoeye \& De Gueldre, G. (2007). Operational cost optimisation of MBR Schilde. Proceedings of the $4^{\text {th }}$ IWA International Membranes Conference, Membranes for Water and Wastewater Treatment, Harrogate, UK, May 15-17.

Icon. (2008). The 2009-2014 world outlook for membrane bioreactor (MBR) systems for wastewater treatment. Icon Group Publications.

Judd, S. (2008). The status of membrane bioreactor technology. Trends in Biotechnology, Vol. 26, No. 2, pp. 109-116.

Judd, S. (2010). The MBR Book. Principles and Applications of Membrane Bioreactors in Water and Wastewater Treatment, Elvesier, ISBN: 978-0-08-096682-3, 2nd Ed, London.

Laera, G.; Pollice, A.; Saturno, D.; Giordano, C.; Lopez, A. (2005). Zero net growth in a membrane bioreactor with complete sludge retention. Water Research, Vol. 30 No. 20, pp. 5241-5249.

Le-Clech, P.; Chen, V. \& Fane, T.A.G. (2006). Fouling in membrane bioreactors used in wastewater treatment. Journal of Membrane Science, Vol. 284, pp. 17-53.

Le-Clech, P.; Fane, A.; Leslie, G. \& Childress, A. (2005b). The operator's perspective. Filtration \& Separation, Vol. 42, pp. 20-23.

Le-Clech, P.; Jefferson, B. \& Judd, S. J. (2005a). A comparison of submerged and sidestream tubular membrane bioreactor configurations. Desalination, Vol. 173, pp. 113-122.

Lesjean, B.; Ferre, V. ; Vonghia, E. \& Moeslang, H. (2009). Market and design considerations of the 37 larger MBR plants in Europe. Desalination Water Treat., Vol. 6, pp. 227-233.

Lowry, O.H.; Rosebrough, N.H.; Farr, A.L. \& Randall, R.J. (1951). Protein measurement with the Folin phenol reagent. J. Biol. Chem., Vol. 193, pp. 265-275.

Masse, A., Sperandio, M. \& Cabassud, C. (2006). Comparison of sludge characteristics and performance of submerged membrane bioreactor and an activated sludge process at high solids retention time. Water Research, Vol. 40, pp. 2405-2415.

Meng, F.; Chae. S-R.; Drews, A.; Kraume, M.; Shin, H-S.; Yang, F. (2009). Recent advances in membrane bioreactors (MBRs): Membrane fouling and membrane material. Water Research, Vol. 43, pp.1489-1512.

Pearce, G. (2008). Introduction to membranes - MBRs: Manufacturers' comparison: part 1, Filtration \& Separation, Volume 45, pp. 28-31

Pirt, S.J. (1965). The maintenance energy of bacteria in growing cultures. Proc. R. Soc. London, Vol. 163B, pp. 224-231.

Pollice A., Giordano, C., Laera, G., Saturno, D. \& Mininni, G. (2007). Physical characteristics of the sludge in a complete retention membrane bioreactor. Water Research, Vol. 41, pp. 1832-1840.

Pollice A., Laera, G. \& Blonda, M. (2004). Biomass growth and activity in a membrane bioreactor with complete sludge retention. Water Research, Vol. 38, pp. 1799-1808.

Rodde-Pellegrin M.L.; Winieswski, C.; Gramick, A.; Tazi, A. \& Buisson, H. (2002). Respirometric needs of heterotrophic populations developed in an immersed membrane bioreactor working in sequenced aeration, Biochemical Engineering Journal, Vol. 11, pp. 2-12.

Rosenberger, S.; Krüger, U.; Witzig, R.; Manz, W.; Szewzyk, U.; Kraume, M. (2002a) Performance of a bioreactor with submerged membranes for aerobic treatment of municipal waste water. Water Research, Vol. 36, pp. 413-420.

Rosenberger, S.; Kubin, K. \& Kraume, M. (2002b). Rheology of activated sludge in membrane bioreactors, Engineering in Life Sciences. Vol. 2, No. 9, pp. 269-275. 
Rosenberger, S.; Laabs, C.; Lesjean, B.; Gnirss, R.; Amy, G.; Jekel, M. \& Schorotter, J.C. (2006). Impact of colloidal and soluble organic material on membrane performance in membrane bioreactors for municipal wastewater treatment, Water Research, Vol. 40, pp. 710-720.

Santos, A. \& Judd, S. (2010). The commercial status of membrane bioreactor for municipal wastewater. Separation Science and Technology, Vol. 45, No. 7, pp-850-857.

Santos, A; Ma, W. \& Judd, S. (2010). Membrane bioreactors: Two decades of research and implementation. Desalination (in press), doi:10.1016/j.desal.2010.07.063.

Smith, P.; Vigneswaran, S.; Ngo, H.; Nguyen \& H. Ben-Aim, R. (2006). Application of an automation system and a supervisory control and data acquisition (SCADA) system for the optimal operation of a membrane adsorption hybrid system. Water Science and Technology, Vol. 53, No. 179.

Sponza, D.T. (2002). Extracellular polymer substances and physicochemical properties of flocs in steady- and unsteady-state activated sludge systems. Process Biochemistry, Vol. 37, pp. 983-98.

Tao, G.; Kekre, K.; Oo, M-H.; Viswanath, B.; Lew, C-H.; Kan, L-M. \& Seah, H. (2009). Large scale membrane bioreactor plant design (retrofit) and optimisation. Proceedings of the $4^{\text {th }}$ IWA Membrane Technology Conference, Beijing, China, Sept 1-3.

Trusell, R.; Merlo, R.; Hermanowicz, S. \& Jenkins, D. (2006). The effect of organic loading on process performance and membrane fouling in a submerged membrane bioreactor treating municipal wastewater. Water Research, Vol. 40, pp. 2675-2683.

Van Loosdrecht, M.C.M. \& Hence, M. (1999). Maintenance, endogenous respiration, lysis, decay and predation. Water Science and Technology. Vol. 39, No.1, pp. 107-117.

Vanrolleghem P.A., van Daele, M. \& Dochain, D. (1995). Practical identifiability of a biokinetic model of activated sludge respiration. Water Research, Vol. 29, pp. 2561-2570.

Verrecht, B.; Judd, S.; Guglielmi, G.; Mulder, J. W. \& Brepols, C. (2008). An aeration energy model for an immersed membrane bioreactor. Water Research, Vol. 42, pp. 47614770.

Verrecht, B.; Maere, T.; Nopens, I.; Brepols, C. \& Judd, S. (2010). The cost of a large-scale hollow fibre MBR. Water Research, Vol. 44, No. 18, pp. 5274-5283

Wei, Y.; van Houten, R.T.; Borger, A.R.; Eikelboom, D.H. \& Fan, Y. (2003). Minimization of excess sludge production for biological wastewater treatment. Water Research, Vol. 37, pp. 4453-4467.

Wicaksana, F.; Fane, A.G. \& Chen, V. (2006). Fibre movement induced by bubbling using submerged hollow fibre membranes, Journal of Membrane Science, Vol. 271, pp. 186195.

Wilén, B-M.; Nielsen, J.; Keiding, K. \& Nielsen, P. (2000). Influence of microbial activity on the stability of activated sludge flocs. Colloids and Surfaces B: Biointerfaces, Vol. 18, No. 2, pp. 145-156.

Wu, J., Le-Clech P., Stuetz, R., Fane, A., Chen, V. (2008). Effects of relaxation and backwashing conditions on fouling in membrane bioreactor. Journal of Membrane Science, Vol. 324, pp. 26-32.

Zhang S. (2000). Polluted water treatment by the combining processes of membrane separation and biodegradation. PhD thesis, Research Centre for Eco-Environmental Sciences, Chinese Academy of Sciences, China. 


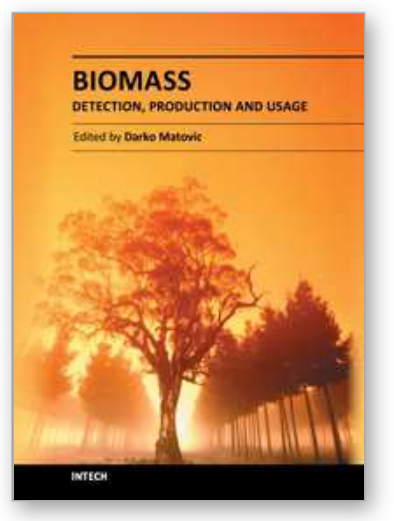

\author{
Biomass - Detection, Production and Usage \\ Edited by Dr. Darko Matovic
}

ISBN 978-953-307-492-4

Hard cover, 496 pages

Publisher InTech

Published online 09, September, 2011

Published in print edition September, 2011

Biomass has been an intimate companion of humans from the dawn of civilization to the present. Its use as food, energy source, body cover and as construction material established the key areas of biomass usage that extend to this day. Given the complexities of biomass as a source of multiple end products, this volume sheds new light to the whole spectrum of biomass related topics by highlighting the new and reviewing the existing methods of its detection, production and usage. We hope that the readers will find valuable information and exciting new material in its chapters.

\title{
How to reference
}

In order to correctly reference this scholarly work, feel free to copy and paste the following:

Sebastián Delgado, Rafael Villarroel, Enrique González and Miriam Morales (2011). Aerobic Membrane Bioreactor for Wastewater Treatment - Performance Under Substrate-Limited Conditions, Biomass -

Detection, Production and Usage, Dr. Darko Matovic (Ed.), ISBN: 978-953-307-492-4, InTech, Available from: http://www.intechopen.com/books/biomass-detection-production-and-usage/aerobic-membrane-bioreactor-forwastewater-treatment-performance-under-substrate-limited-conditions

\section{INTECH}

open science | open minds

\section{InTech Europe}

University Campus STeP Ri Slavka Krautzeka 83/A 51000 Rijeka, Croatia Phone: +385 (51) 770447

Fax: +385 (51) 686166 www.intechopen.com

\section{InTech China}

Unit 405, Office Block, Hotel Equatorial Shanghai No.65, Yan An Road (West), Shanghai, 200040, China 中国上海市延安西路65号上海国际贵都大饭店办公楼405单元 Phone: +86-21-62489820

Fax: $+86-21-62489821$ 
(C) 2011 The Author(s). Licensee IntechOpen. This chapter is distributed under the terms of the Creative Commons Attribution-NonCommercialShareAlike-3.0 License, which permits use, distribution and reproduction for non-commercial purposes, provided the original is properly cited and derivative works building on this content are distributed under the same license. 